\title{
Anionic Dye Removal by Polypyrrole-Modified Red Mud and Its Application to a Lab-Scale Column: Adsorption Performance and Phytotoxicity Assessment
}

\author{
Feng Zhang, ${ }^{1}$ Yue Yin $\mathbb{D}^{1},{ }^{1}$ Chunlei Qiao $\mathbb{D}^{1},{ }^{1}$ Ya-nan Luan $\left(\mathbb{D},{ }^{1}\right.$ Mengyan Guo $\mathbb{D},{ }^{1}$ Yihua Xiao, \\ and Changqing Liu $\mathbb{D}^{1,2}$
}

${ }^{1}$ School of Environmental and Municipal Engineering, Qingdao University of Technology, Qingdao 266033, China

${ }^{2}$ Qingdao Research Center of Urban Water Environmental Pollution Control, Qingdao 266033, China

Correspondence should be addressed to Changqing Liu; lcqlfyqut@126.com

Feng Zhang and Yue Yin contributed equally to this work.

Received 8 August 2021; Revised 27 September 2021; Accepted 4 October 2021; Published 1 November 2021

Academic Editor: Hesham Hamad

Copyright (c) 2021 Feng Zhang et al. This is an open access article distributed under the Creative Commons Attribution License, which permits unrestricted use, distribution, and reproduction in any medium, provided the original work is properly cited.

In this study, polypyrrole-modified red mud (PRM) was prepared for the efficient removal of anionic dyes (methyl orange and Congo red) from aqueous solutions. The phytotoxicity (bean sprouts) of the dye solution before and after dye removal was investigated. Adsorption kinetics confirmed that the adsorption of methyl orange (MO) and Congo red (CR) on PRM was controlled by chemical reactions between the functional groups of polypyrrole and dyes. From Langmuir isotherm fitting, we found the theoretical adsorption capacities of MO and CR on PRM were 194.1 and $314.9 \mathrm{mg} / \mathrm{g}$, respectively. The adsorption progress of MO and CR on PRM was found to be spontaneous and endothermic. The column studies demonstrated that, under dynamic flow, the PRM can efficiently remove MO and CR from aqueous solution, with adsorption capacities of 31.08 and $55.04 \mathrm{mg} / \mathrm{g}$, respectively. In the toxicity test, the phytotoxicity of the column effluents (after dye removal) was significantly lowered compared to the initial dye influents. After the removal of MO and CR, the average root length of bean sprouts was increased from $3.30 \mathrm{~cm}$ to $5.18 \mathrm{~cm}$ and from $3.01 \mathrm{~cm}$ to $7.00 \mathrm{~cm}$, respectively. These findings highlighted the efficient removal of dyes by PRM from aqueous solution, demonstrating the possible application of PRM for the removal of dye from dye-contaminated wastewaters.

\section{Introduction}

Different types of contaminations in water bodies pose great threat to the environment and society $[1,2]$. Among these contaminations, organic dyes are highly noteworthy because over 40,000 types of organic dyes are fabricated and widely used in a lot of industrial including textile, paper, and leather [3]. Due to inappropriate treatment process, large amount of dyes together with industrial wastewater are discharged into natural water bodies $[4,5]$. The presence of dyes in the aqueous solutions poses a huge threat to the environmental livings because they have been confirmed to be carcinogenicity, genotoxicity, and neurotoxicity $[6,7]$. Among these dyes, there are more than 7,000 different synthetic chemical molecules involved which are nonbiodegradable under environ- mental conditions [7, 8]. Hence, the sufficient removal of organic dyes before discharging into water bodies is of great significance to environmental safety.

Recently, different technologies have been investigated for the treatment of dye-contaminated wastewater including, coagulation, chemical oxidation, photocatalysis, and adsorption [9-12]. Among these technologies, adsorption progress has been confirmed to be a reliable and effective solution for dye removal from aqueous solutions $[13,14]$. The removal of Congo red (CR) by using N,N-dimethyl dehydroabietylamine oxide-modified zeolites was investigated by Liu et al., and they found that the adsorption capacity of CR on modified zeolites was $69.9 \mathrm{mg} / \mathrm{g}$ [6]. Zhang et al. studied the dye adsorption capacity by g-C3N4/graphene oxide-wrapped sponge monoliths [15]. Most of these studies showed 
TABLE 1: Characteristics and structures of methyl orange and Congo red.

\begin{tabular}{lcccccc}
\hline Generic name & Abbreviation & $\begin{array}{c}\lambda_{\max } \\
(\mathrm{nm})\end{array}$ & $\begin{array}{c}\text { Molecular weight } \\
(\mathrm{g} / \mathrm{mol})\end{array}$ \\
Methyl orange & $\mathrm{MO}$ & 497 & Molecular formula \\
Congo red & $\mathrm{CR}$ &
\end{tabular}

promising dye adsorption performance; however, few have calculated the potential cost of the fabricated adsorbents. With expensive raw materials used (such as precious metals), the cost of these adsorbents is not acceptable under real conditions. Hence, it is crucial for researchers to find affordable alternatives for the removal of dye from dyecontaminated wastewaters.

Red mud (RM), which is a by-product of aluminum industry, has been recognized as a hazardous waste due to its difficulty of disposal and large volumes [16]. The inappropriate placements of RM have caused several severe accidents in China and around the world. However, recent researches proposed that the red mud could be used as raw material of adsorbent due to its high content of iron and aluminum; this could transfer the "wastes" into "resources" and reduce the cost of raw materials. Successful fabrications of red mud-based adsorbents have been developed for the removal of fluoride [17], arsenic [18], antibiotics [19, 20], phosphate [21], and dyes [22].

In this manuscript, we report a detailed application of polypyrrole-modified red mud (PRM) as adsorbent for the removal of anionic dyes: methyl orange (MO) and CR. The morphology features of PRM were characterized by scanning electron microscopy (SEM), Fourier transform infrared spectroscopy (FT-IR), and energy-dispersive X-ray spectroscopy (EDS). The effects of initial $\mathrm{pH}$, dye concentration, adsorbent dosage, adsorption time, and adsorption temperature were investigated through batch studies. A continuous-flow column study was designed and operated to investigate the adsorption performance of both dyes onto PRM under dynamic condition. Furthermore, the phytotoxicity of the column effluents was assessed. The objectives of this study are to (i) investigate the adsorption performance of $\mathrm{MO}$ and CR onto PRM in batch and column studies, (ii) elucidate the proper mechanisms by model fittings and adsorbent characteristics, and (iii) characterize the dye detoxication ability of PRM. The research provided a useful reference for future researches in dye adsorbent fabrications and application evaluations.

\section{Materials and Methods}

2.1. Materials. Methyl orange and Congo red are purchased from Ourchem Co., Ltd (Shanghai, China). The characteristics and structure of these two dyes are listed in Table 1.
Other used chemicals are purchased from Sinopharm Chemical Reagent Co., Ltd, China, including ferric sulfate, $\mathrm{HCl}, \mathrm{NaOH}$, pyrrole, and methyl alcohol. All the used chemicals are of analytical grade and without further purification. Deionized water is used in all experiments. Red mud is collected from an alumina industry in Shandong province. Orion Star ${ }^{\mathrm{TM}}$ A211 (Thermo Fisher) is used in this study for $\mathrm{pH}$ adjustment.

2.2. Preparation of PRM Adsorbents. The PRM adsorbents are prepared using optimized procedures based on early studies [23, 24]. First, pyrrole solution is prepared using $0.6 \mathrm{~mL}$ pyrrole diluted into $100 \mathrm{~mL}$ with deionized water. Then, 2.5 red mud is added into $30 \mathrm{~mL}$ pyrrole solution and mixed in a rotator mixer for $1 \mathrm{~h}$. After 1 hour of complete mixing, $1.25 \mathrm{~g}$ ferric sulfate is added into the solution. Finally, the red mud is rinsed with methyl alcohol and deionized water for several times until the supernatant reaches neutral and dried in an oven; the obtained PRM is collected in a desiccator for future use.

2.3. Adsorption Experiments. Batch and column studies are conducted to investigate the adsorption performance of both dyes onto PRM under static and dynamic conditions. $1000 \mathrm{mg} / \mathrm{L}$ of MO and CR stock solutions are prepared and stored in the refrigerator. The dye solutions of $10-100 \mathrm{mg} / \mathrm{L}$ are prepared by dilution of stock solutions. The $\mathrm{pH}$ of the dyes is adjusted by adding $0.1 \mathrm{M} \mathrm{HCl}$ or $0.1 \mathrm{M} \mathrm{NaOH}$.

For static experiments, certain amount of PRM is added to $100 \mathrm{~mL}$ conical flasks with $50 \mathrm{~mL}$ of dye solutions. The flasks are sealed with parafilm and placed in a thermostatic orbital shaker with a shaking speed of $120 \mathrm{rpm}$ (temperature is maintained constant). The concentrations of dyes are determined by a UV-Vis spectroscopy at $497 \mathrm{~nm}$ for MO and $464 \mathrm{~nm}$ for CR (DR2800, HACHI). All experiments are conducted in duplicates, and the data are average. The adsorption capacity $q_{e}$ of PRM and removal rate $R$ are calculated as follows:

$$
\begin{aligned}
& q_{e}=\frac{\left(C_{0}-C_{e}\right)}{a}, \\
& R=\frac{\left(C_{0}-C_{e}\right)}{C_{0}} \times 100 \%,
\end{aligned}
$$




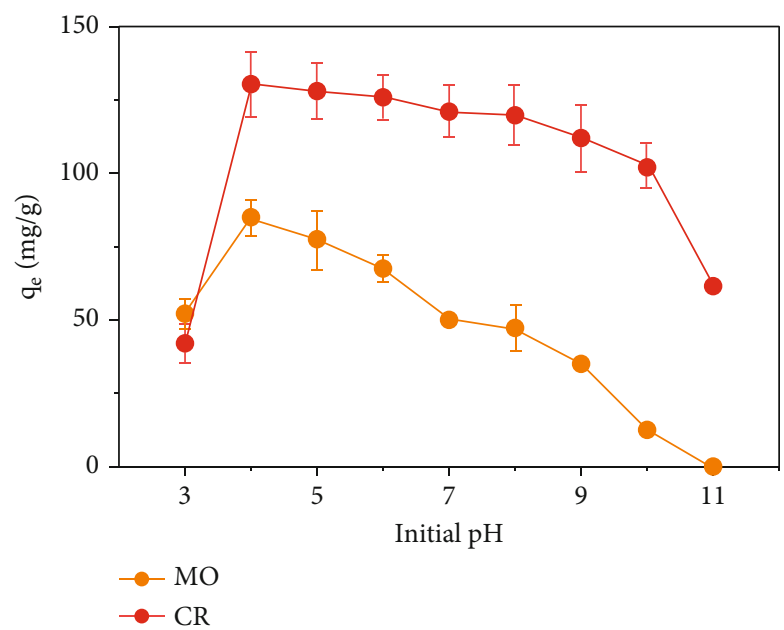

(a)

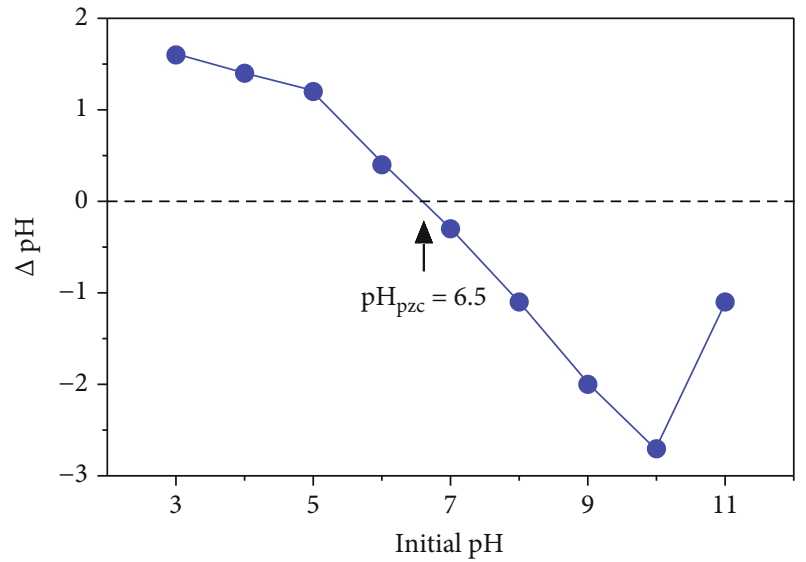

(b)

FIGURE 1: (a) Effect of initial $\mathrm{pH}$ on $\mathrm{MO}$ and $\mathrm{CR}$ adsorption; (b) $\mathrm{pH}_{\mathrm{pzc}}$ of the adsorbent (experiment conditions: initial concentration = 100 $\mathrm{mg} / \mathrm{L}$ and dosage $=0.5 \mathrm{~g} / \mathrm{L}$ ).

where $C_{0}$ and $C_{e}$ are the dye concentration at initial stage and equilibrium stage $(\mathrm{mg} / \mathrm{L})$ and $a(\mathrm{~g} / \mathrm{L})$ is the dosage of PRM.

For dynamic experiments, a laboratory-scale column (bed volume $\sim 5.5 \mathrm{~mL}$ ) is used (Fig. S1). The concentration of feed solutions is maintained at $50 \mathrm{mg} / \mathrm{L}$ for both dyes, and the effluents are collected and determined. The phytotoxicity assessment of the effluents is conducted using the methods proposed by Patra et al. [25]. Specifically, bean sprout beads are selected as the indicator of phytotoxicity assessment. The dried beads are initially washed with $1 \%$ sodium hypochlorite and deionized water and then airdried under room temperature. After that, the beads are planted on cotton soaked with solution (deionized water and dye solution with or without adsorption treatment) and allowed to germinate under dark conditions for 4 days. All experiments were conducted by triplicates, and the relative standard deviations were below $8 \%$.

2.4. Adsorption Models. To better interpret the adsorption mechanism during the adsorption progress, several adsorption models are fitted in this research. Pseudo-first-order (Equation (3)), pseudo-second-order (Equation (4)), and intraparticle diffusion (Equation (5)) are three classical kinetic models to reveal the adsorption progress, and $h$ is the related initial adsorption rate. The equations are listed as follows:

$$
\begin{aligned}
\ln \left(q_{e}-q_{t}\right) & =\ln q_{e}-K_{1} t, \\
\frac{t}{q_{t}} & =\frac{1}{K_{2} q_{e}^{2}}+\frac{t}{q_{e}}, \\
q_{t} & =K_{d} t^{1 / 2}+C, \\
h & =q_{e}^{2} K_{2},
\end{aligned}
$$

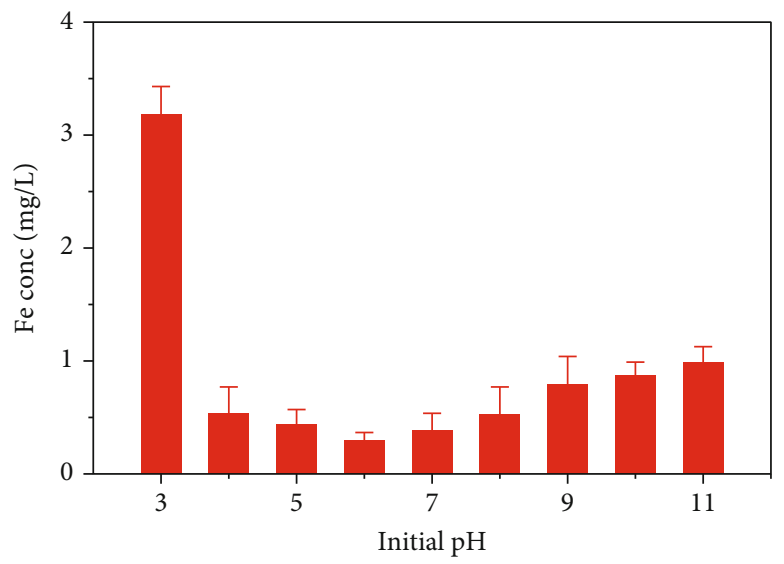

FIgURE 2: Effect of initial $\mathrm{pH}$ on dissolved Fe concentration (experiment condition: dosage $=1 \mathrm{~g} / \mathrm{L}$ ).

where $q_{e}$ and $q_{t}$ are the adsorption capacity of the PRM at equilibrium and at different times $(\mathrm{mg} / \mathrm{g}) . t(\mathrm{~min})$ is the adsorption time. $K_{1}\left(\mathrm{~min}^{-1}\right), K_{2}(\mathrm{~g} / \mathrm{mg} / \mathrm{min})$, and $K_{d}$ $\left(\mathrm{mg} / \mathrm{g} / \mathrm{min}^{1 / 2}\right)$ are the kinetic rate constants.

Adsorption isotherms for both dyes onto PRM are fitted using Langmuir model (Equation (7)), Freundlich model (Equation (8)), and Temkin mode (Equation (9)). The equations are listed as follows:

$$
\begin{aligned}
& q_{e}=\frac{q_{m} K_{L} C_{e}}{1+K_{L} C_{e}}, \\
& q_{e}=K_{F} C_{e}^{1 / n}, \\
& q_{e}=K_{T} \ln \left(f C_{e}\right),
\end{aligned}
$$

where $q_{m}(\mathrm{mg} / \mathrm{g})$ is the theoretical maximum adsorption capacity of PRM; $K_{L}(\mathrm{~L} / \mathrm{mg}), K_{F}(\mathrm{mg} / \mathrm{g})$, and $K_{T}(\mathrm{~J} / \mathrm{mol})$ are the constants of Langmuir, Freundlich, and Temkin 


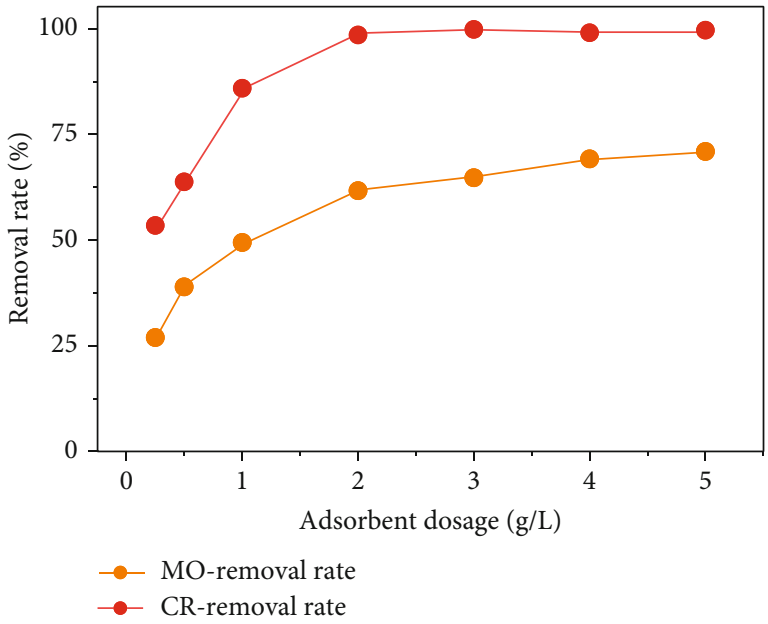

(a)

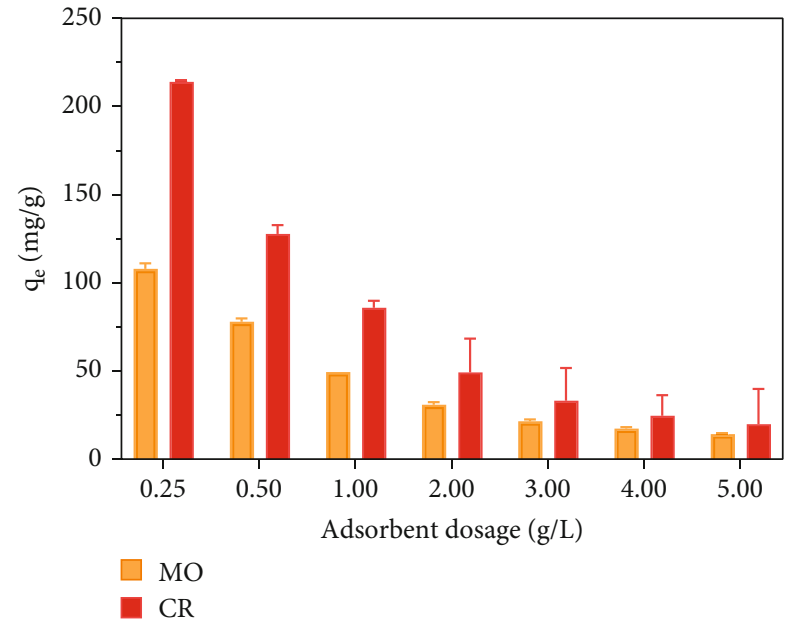

(b)

Figure 3: (a) Effect of adsorbent dosage on MO and CR removal; (b) dye adsorption capacity at different adsorbent dosages (experiment conditions: initial concentration $=100 \mathrm{mg} / \mathrm{L}, \mathrm{pH}=4$ ).

isotherms. $n$ represents the adsorption intensity, and $f$ $(\mathrm{L} / \mathrm{mg})$ is the Temkin binding energy.

For further evaluation of the adsorption progress, dimensionless factor $R_{L}$ derived from Langmuir isotherm is calculated. This constant represents whether the progress is favorable or unfavorable. If $0<R_{L}<1$, the adsorption progress is favorable; otherwise, it will be unfavorable.

$$
R_{L}=\frac{1}{1+K_{L} C_{0}}
$$

Temperature is a vital parameter in adsorption progress; the effects of different operating temperatures $(288.15 \mathrm{~K}$, $298.15 \mathrm{~K}$, and $308.15 \mathrm{~K}$ ) are investigated in this research. The adsorption thermodynamic is revealed by the widely used Van't Hoff equation as follows [26]:

$$
\begin{gathered}
\Delta G^{0}=-R T \ln \frac{q_{e}}{C_{e}}, \\
\Delta G^{0}=\Delta H^{0}-T \Delta S^{0},
\end{gathered}
$$

where $\Delta G^{0}$ is the free energy change $(\mathrm{kJ} / \mathrm{mol}), R$ is the ideal gas constant $(\mathrm{kJ} / \mathrm{mol} / \mathrm{K})$, and $T$ is the solution temperature $(\mathrm{K}) . \Delta H^{0}(\mathrm{~kJ} / \mathrm{mol})$ and $\Delta S^{0}(\mathrm{~kJ} / \mathrm{mol} / \mathrm{K})$ are referred to standard enthalpy and standard entropy.

In order to predict and evaluate the adsorption performance in column studies, the Thomas model is used in this research. The Thomas model assumes that the adsorption progress by mass transfer processes at the interphase species which can be expressed as follows $[27,28]$ :

$$
C(t)=\frac{C_{0}}{1+\exp \left(k_{\mathrm{th}} q_{\mathrm{th}} m / Q-k_{\mathrm{th}} C_{0} t\right)},
$$

where $k_{\text {th }}(\mathrm{mL} / \mathrm{mg} / \mathrm{min})$ and $q_{\mathrm{th}}(\mathrm{mg} / \mathrm{g})$ are the rate constant and theoretical maximum adsorption capacity of the
Thomas model, $m(\mathrm{~g})$ is the adsorbent dosage, and $Q$ $(\mathrm{mL} / \mathrm{min})$ is the flow velocity of influents.

2.5. Adsorbent Characterization. The surface morphology was determined by SEM (SU8010, Hitachi, Japan). The EDS was detected by ZEISS SEM (Gemini 300, Germany). FT-IR spectrophotometer (Thermo Fisher, USA) was used to analyze the functional groups of the adsorbents.

\section{Results and Discussion}

3.1. Characterization of PRM. SEM images and FT-IR spectrum of raw red mud and PRM are given in Fig. S2\&3. The polypyrrole modification improved the roughness of the adsorbent surface, with increased granular-like morphology occurred on the surface of PRM. In FT-IR spectrum, the pyrrole monomer ring at antisymmetric and symmetric stretching vibrations was observed around 1540 and $1460 \mathrm{~cm}^{-1}$ [29]. Moreover, the band at 880 and $680 \mathrm{~cm}^{-1}$ was related to $\mathrm{C}-\mathrm{H}$ and $\mathrm{N}-\mathrm{H}$ bending vibrations. These results confirm the successful modification of polypyrrole onto the red mud. The SEM images and EDS of PRM after adsorption of MO and CR are shown in Fig. S4 and Fig. S5. The increase of S element in EDS confirmed the successful adsorption of MO and CR. After adsorption, the surface of PRM turned to a uniform and smooth surface without evident pores. Thus, in compliance with EDS results, it can be confirmed that both dyes are adsorbed onto the surface PRM.

3.2. Effect of Initial $p H$ and Dosage. Before investigating the adsorption performance of MO and CR onto PRM, the effect of initial solution $\mathrm{pH}$ and adsorbent dosage should be thoroughly assessed due to their significant influence on adsorption progress [30]. The effect of initial solution $\mathrm{pH}$ on $\mathrm{MO}$ and $\mathrm{CR}$ adsorption is studied in the $\mathrm{pH}$ range from 3 to 11. In order to better understand the effect of initial solution $\mathrm{pH}$ on adsorbent itself, the point of zero charge $\left(\mathrm{pH}_{\mathrm{pzc}}\right)$ of 

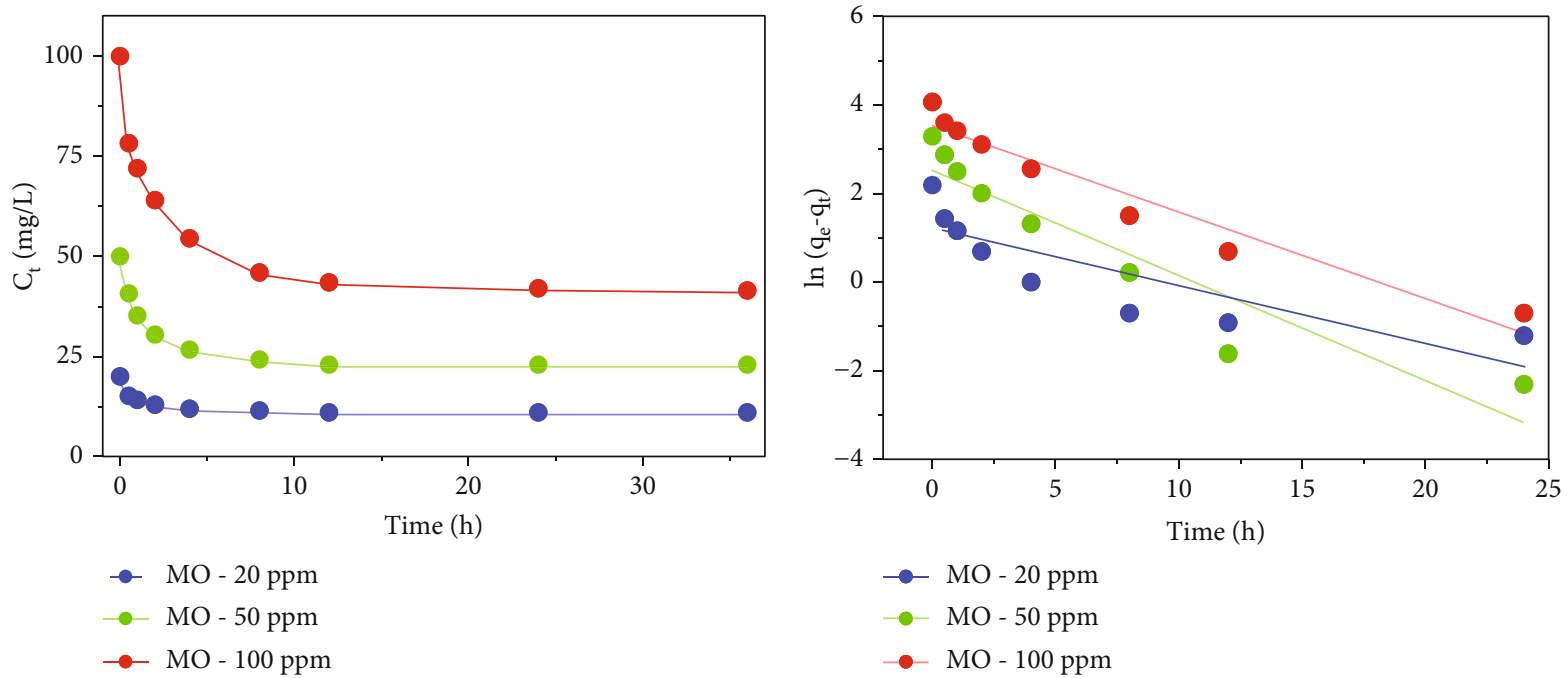

(a)
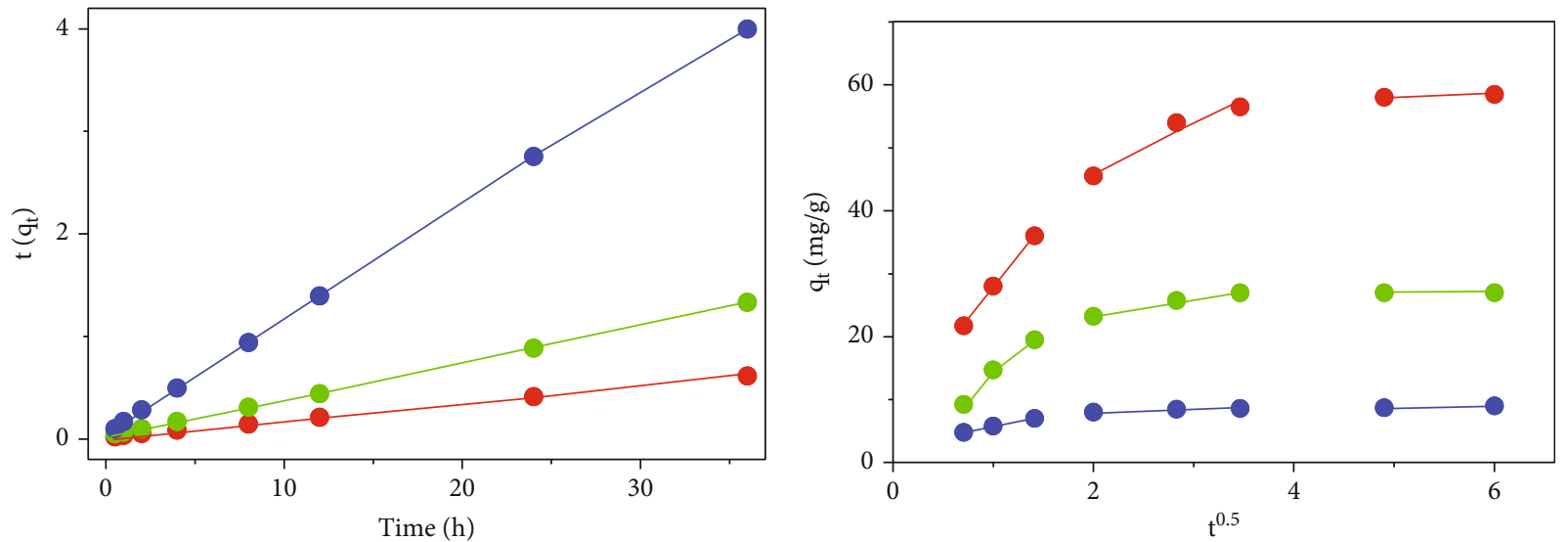

(c)

(d)
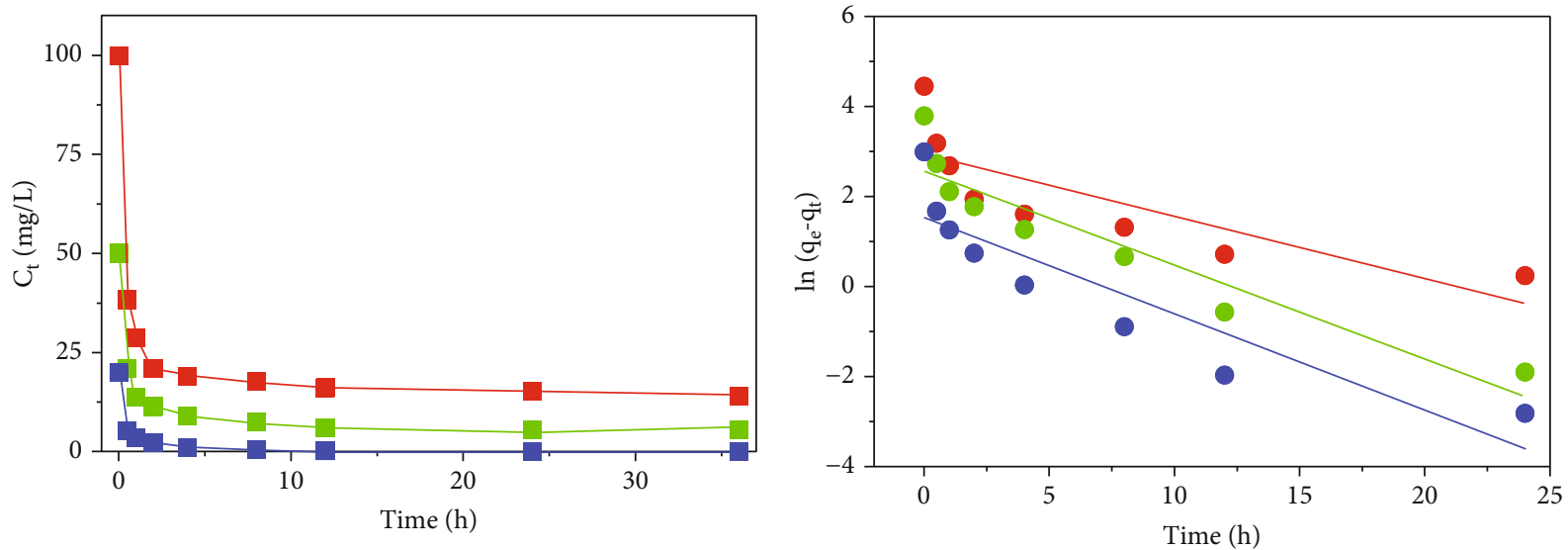

$$
\begin{aligned}
& \rightarrow \mathrm{CR}-20 \mathrm{ppm} \\
& -\mathrm{CR}-50 \mathrm{ppm} \\
& -\mathrm{-CR}-100 \mathrm{ppm}
\end{aligned}
$$$$
\begin{aligned}
& -\mathrm{CR}-20 \mathrm{ppm} \\
& -\mathrm{CR}-50 \mathrm{ppm} \\
& -\mathrm{CR}-100 \mathrm{ppm}
\end{aligned}
$$

(e)

Figure 4: Continued. 


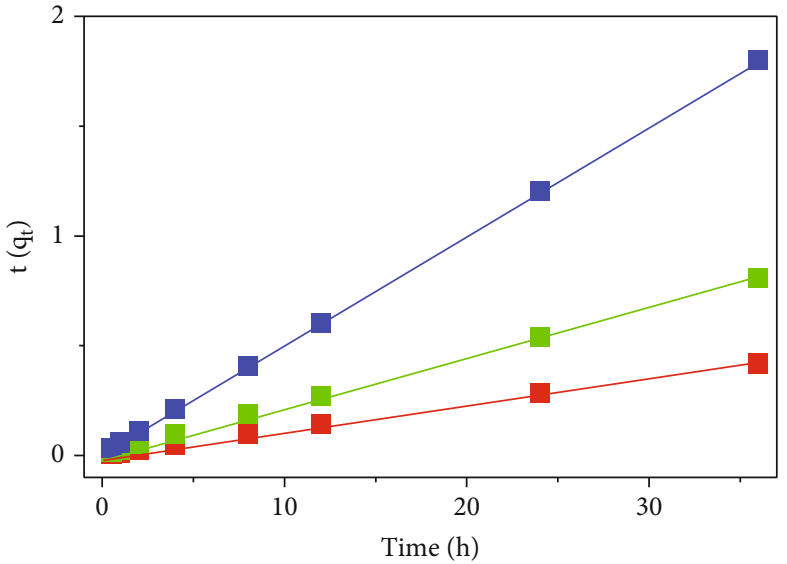

(g)

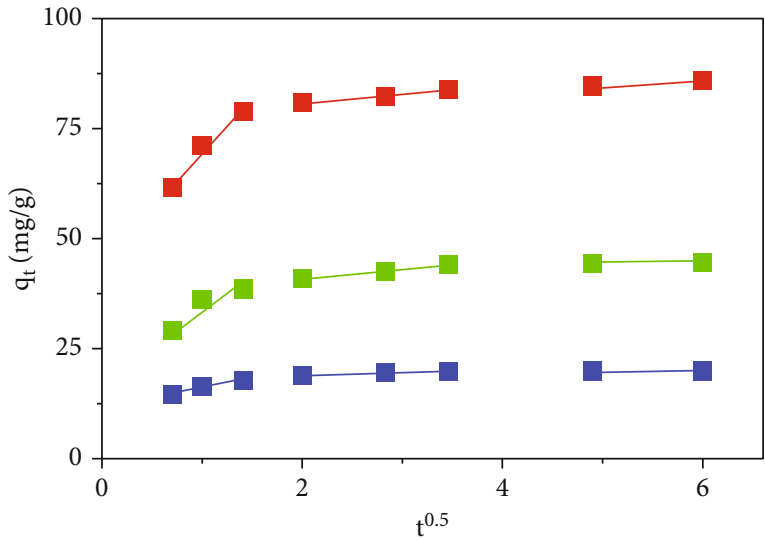

(h)

FIGURE 4: Effect of time on (a, d) MO and CR adsorption, (b, f) pseudo-first-order, (c, g) pseudo-second-order, and (d, h) intraparticle diffusion model fitting of $\mathrm{MO}$ and $\mathrm{CR}$ (experiment conditions: adsorbent dosage $=1 \mathrm{~g} / \mathrm{L}, \mathrm{pH}=4$ ).

TABLE 2: Kinetic parameters of pseudo-first-order and pseudo-second-order.

\begin{tabular}{|c|c|c|c|c|c|c|c|c|c|}
\hline \multirow{2}{*}{\multicolumn{2}{|c|}{$C_{0}(\mathrm{mg} / \mathrm{L})$}} & \multirow[b]{2}{*}{$q_{e}(\mathrm{mg} / \mathrm{g})$} & \multicolumn{3}{|c|}{ Pseudo-first-order constant } & \multirow[b]{2}{*}{$q_{e}(\mathrm{mg} / \mathrm{g})$} & \multicolumn{3}{|c|}{ Pseudo-second-order constant } \\
\hline & & & $q_{e}(\mathrm{mg} / \mathrm{g})$ & $k_{1}\left(\min ^{-1}\right)$ & $R^{2}$ & & $k_{2}(\mathrm{~g} / \mathrm{mg} / \mathrm{min})$ & $h(\mathrm{mg} / \mathrm{g} / \mathrm{min})$ & $R^{2}$ \\
\hline \multirow{3}{*}{ MO } & 20 & 9.10 & 2.39 & 0.0903 & 0.86 & 9.07 & 0.1916 & 15.76 & 0.99 \\
\hline & 50 & 27.10 & 6.89 & 0.1518 & 0.73 & 27.78 & 0.0471 & 36.35 & 0.99 \\
\hline & 100 & 58.50 & 26.95 & 0.1621 & 0.97 & 60.61 & 0.0150 & 55.10 & 0.99 \\
\hline \multirow{3}{*}{ CR } & 20 & 20.00 & 2.71 & 0.1632 & 0.93 & 20.12 & 0.2287 & 92.58 & 0.99 \\
\hline & 50 & 44.60 & 8.57 & 0.1636 & 0.96 & 45.05 & 0.0694 & 140.85 & 0.99 \\
\hline & 100 & 86.00 & 15.85 & 0.1638 & 0.90 & 86.21 & 0.0434 & 322.56 & 0.99 \\
\hline
\end{tabular}

the PRM is also investigated. As shown in Figure 1(a), the adsorption capacities of MO and CR share the same trend, and both achieve highest adsorption capacity at $\mathrm{pH}=4$ and decrease with the increase of $\mathrm{pH}$. These results are in accordance with previous researcher that highest adsorption capacity was achieved at $\mathrm{pH}$ of 2 [25]. At beginning, the adsorption seems to be deteriorated $(\mathrm{pH}=3)$; this is due to the decomposition of the PRM under extremely acid conditions [31]. The effect of initial $\mathrm{pH}$ on the solution iron concentration is displayed in Figure 2. Under $\mathrm{pH}=3$, the $\mathrm{Fe}$ concentration exceeds $3 \mathrm{mg} / \mathrm{L}$ while it remained below $1 \mathrm{mg} / \mathrm{L}$ under other $\mathrm{pH}$ condition. This suggests that the extremely acid condition may lead to a potential decomposition of PRM; hence, future experiments are conducted above $\mathrm{pH}$ of 4 . The $\mathrm{pH}_{\mathrm{pzc}}$ of PRM is around 6.5, which means that the surface of PRM is negatively charged at solution $\mathrm{pH}>$ 6.5 and has a positively charged surface when $\mathrm{pH}$ is lower than 6.5. As previously mentioned, both dyes are typical anionic species which means that the positively charged surface is beneficial to the adsorption progress due to the electrostatic attraction between positively charged surface and negatively charged dyes [32]. The molecular formula of $\mathrm{MO}$ and $\mathrm{CR}$ is given in Table 1; both contain sulphonic acid groups $\left(\mathrm{R}-\mathrm{SO}_{3} \mathrm{Na}\right)$ and turn into sulphonate groups (R$\mathrm{SO}_{3}{ }^{-}$) at lower $\mathrm{pH}$ conditions. This is in accordance with the results in Figure 1(a) while lower $\mathrm{pH}$ results in higher adsorption capacity of both dyes. Therefore, the following experiments are conducted at an initial solution $\mathrm{pH}$ of 4 to achieve the highest adsorption capacity and prevent decomposition of PRM.

The proper adsorbent dosage is considered to be an important influencing factor in the adsorption progress, since it could change the equilibrium system between adsorbent and adsorbate [33]. The influence of adsorbent dosage is carried out with dosage ranging from 0.25 to $5 \mathrm{~g} / \mathrm{L}$, at initial solution $\mathrm{pH}$ of 4 and initial dye concentration of $100 \mathrm{mg} / \mathrm{L}$ for both $\mathrm{MO}$ and CR. As illustrated in Figure 3(a), the removal rates of $\mathrm{MO}$ and $\mathrm{CR}$ increase with dosage ranging from 0.25 to $3 \mathrm{~g} / \mathrm{L}$ and reach equilibrium above $3 \mathrm{~g} / \mathrm{L}$. With the dosage amount increase from $0.25 \mathrm{~g} / \mathrm{L}$, the vacant active sites increased significantly which leads to a higher dye removal rate. Under dosage of $3 \mathrm{~g} / \mathrm{L}$, CR is removed $100 \%$ in the solutions and further increase in adsorbent dosage is unnecessary. However, after dosage of $3 \mathrm{~g} / \mathrm{L}$, the removal rate of $\mathrm{MO}$ reaches equilibrium of around $70 \%$ with no significant signs of continuously increase. This could be due to the interaction behavior between adsorbents when the dosage increases to a certain level, the active sites might be interfered. The adsorption capacity under different absorbent dosage is given in Figure 3(b). It is obvious that higher dosage leads to lower adsorption capacity; hence, in consideration of the removal rate and adsorption capacity, the dosage of $1 \mathrm{~g} / \mathrm{L}$ is chosen in following experiments. 
TABLE 3: Kinetics parameters of intraparticle diffusion model.

\begin{tabular}{cccccccc}
\hline & \multirow{2}{*}{$C_{0}(\mathrm{mg} / \mathrm{L})$} & $K_{d 1}\left(\mathrm{mg} / \mathrm{g} / \mathrm{min}^{1 / 2}\right)$ & $R^{2}$ & $K_{d 2}\left(\mathrm{mg} / \mathrm{g} / \mathrm{min}^{1 / 2}\right)$ & $R^{2}$ & $K_{d 3}\left(\mathrm{mg} / \mathrm{g} / \mathrm{min}^{1 / 2}\right)$ & $R^{2}$ \\
\hline \multirow{3}{*}{ MO } & 20 & 3.10 & 0.99 & 0.42 & 0.92 & 0.27 & 1.00 \\
& 50 & 14.29 & 0.98 & 2.58 & 0.99 & 0.54 & 1.00 \\
& 100 & 20.10 & 0.99 & 7.65 & 0.95 & 0.45 & 1.00 \\
& 20 & 4.51 & 0.97 & 0.62 & 0.98 & 0.05 & 1.00 \\
$\mathrm{CR}$ & 50 & 12.89 & 0.86 & 2.04 & 0.99 & 0.14 & 1.00 \\
& 100 & 24.06 & 0.97 & 2.00 & 0.98 & 1.16 & 1.00 \\
\hline
\end{tabular}

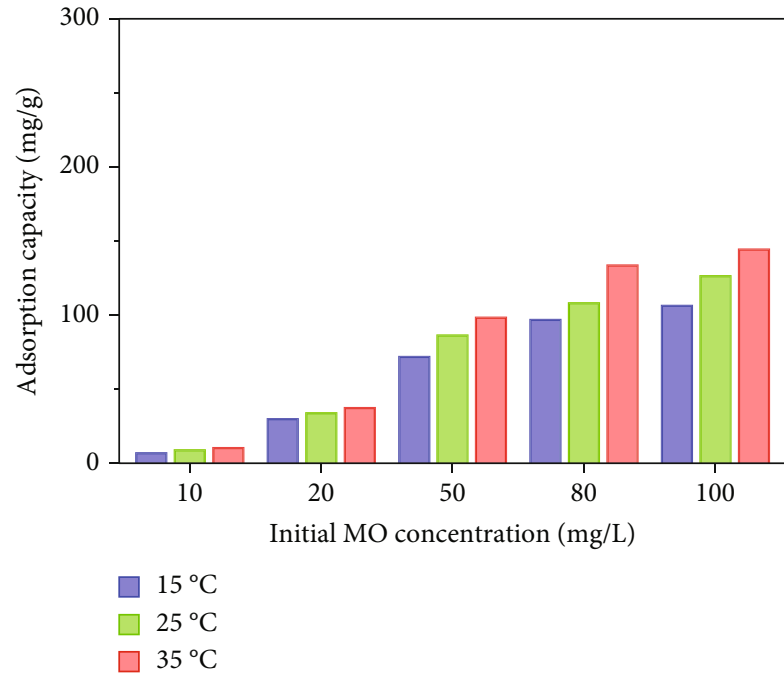

(a)

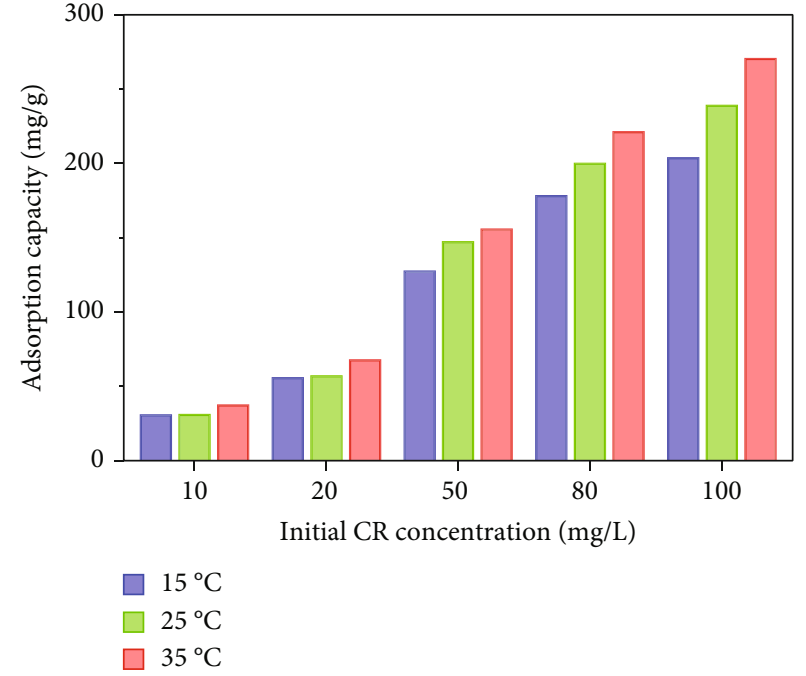

(b)

FIGURE 5: Effect of initial MO and CR concentration on PRM adsorption capacity (experiment conditions: adsorbent dosage $=0.5 \mathrm{~g} / \mathrm{L}$, $\mathrm{pH}=4)$.

3.3. Adsorption Kinetics. The adsorption kinetics are of great significance to evaluating the adsorption efficiency and progress of MO and CR onto PRM during the adsorption [34]. Time-dependent adsorption experiments were carried out with different initial dye concentrations (20, 50, and $100 \mathrm{mg} / \mathrm{L}$ ). As shown in Figures 4(a) and 4(d), the remaining concentrations of $\mathrm{MO}$ and $\mathrm{CR}$ are recorded at different time intervals in $36 \mathrm{~h}$. Obviously, the adsorption reactions show rapid adsorption rates at initial stage and stabilized afterwards [35]. At initial concentration of 20, 50, and $100 \mathrm{mg} / \mathrm{L}$, the equilibrium MO concentration decreased to $11.0,23.0$, and $41.5 \mathrm{mg} / \mathrm{L}$. However, the adsorption of CR is more effective, with equilibrium concentrations plunge to $0.0,5.5$, and $14.0 \mathrm{mg} / \mathrm{L}$. The possible mechanism is that $\mathrm{MO}$ and $\mathrm{CR}$ have different molecular weights (MW), with the MW of CR reaches $696.7 \mathrm{~g} / \mathrm{mol}$ which is twice that of MO. Hence, the adsorption capacities for MO and CR are comparable in terms of adsorbed molecules $(\mathrm{mM} / \mathrm{g})$.

The fitting parameters of pseudo-first-order, pseudo-second-order, and intraparticle diffusion model are summarized in Tables 2 and 3. For pseudo-first-order model, the calculated $q_{e}$ value is significantly different from the experimental value, and the correlation coefficients $\left(R^{2}\right)$ are not satisfying in both MO and CR data. By contrast, the calculated $q_{e}$ value in pseudo-second-order model is nearly close to the experimental value and each $R^{2}$ value is above 0.99 for different initial concentration of MO and CR (Figures 4(b) and 4(e)). Hence, it can be concluded that the dye adsorption progress is controlled by chemical reactions, and the rate $k_{2}$ and $h$ could be used to describe the removal rates of MO and CR [36]. The removal kinetics of $\mathrm{MO}$ are clearly slower than $\mathrm{CR}$, and the $k_{2}$ value in pseudo-second-order of CR adsorption is higher than $\mathrm{MO}$ in every initial dye concentration. More importantly, the initial adsorption rate $h$ of CR adsorption is significantly higher (i.e., with at least three times higher). After 1 hour adsorption of $100 \mathrm{mg} / \mathrm{L}$ dyes by PRM, the CR concentration is lowered to $28.7 \mathrm{mg} / \mathrm{L}$ while the $\mathrm{MO}$ concentration remains at $72.0 \mathrm{mg} / \mathrm{L}$. This confirms the rapid removal capacity of CR by PRM adsorbent.

The fitting of intraparticle diffusion model is shown in Table 3. The adsorption progress of dyes onto PRM can be divided into three stages; the first stage of fitted MO adsorption lines almost passes the origin while CR adsorption fitted lines could not pass, suggesting that the intraparticle diffusion plays a dominant role in MO adsorption onto PRM (likely the rate-limiting step) $[8,37]$. For CR adsorption onto PRM, the adsorption progress could be jointly controlled by external mass transfer and intraparticle diffusion. 


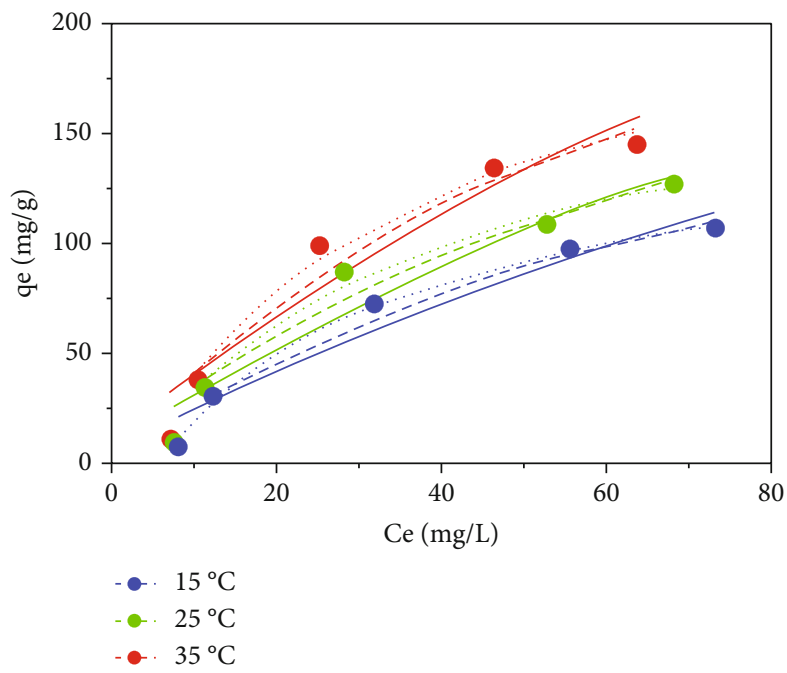

(a)

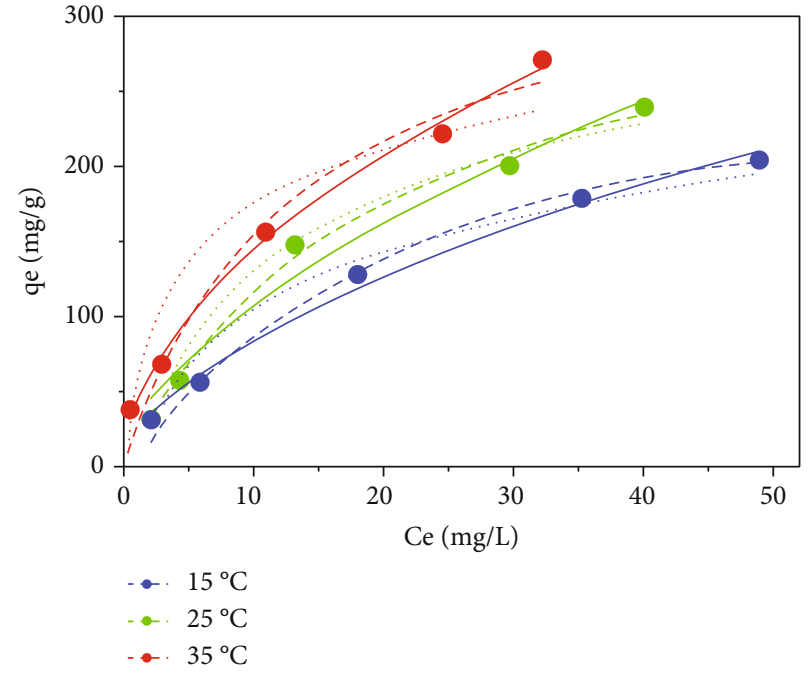

(b)

FIGURE 6: Isotherm fittings of (a) MO adsorption and (b) CR adsorption onto PRM (Langmuir isotherm: dash line, Freundlich isotherm: connecting line, and Temkin isotherm: dotted line) (experiment conditions: adsorbent dosage $=0.5 \mathrm{~g} / \mathrm{L}, \mathrm{pH}=4$ ).

TABLE 4: Kinetics parameters of Langmuir, Freundlich, and Temkin models.

\begin{tabular}{|c|c|c|c|c|c|c|c|c|c|c|c|}
\hline & \multirow{2}{*}{$T\left({ }^{\circ} \mathrm{C}\right)$} & \multicolumn{4}{|c|}{ Langmuir constant } & \multicolumn{3}{|c|}{ Freundlich constant } & \multicolumn{3}{|c|}{ Temkin constant } \\
\hline & & $q_{\max }(\mathrm{mg} / \mathrm{g})$ & $k_{L}(\mathrm{~L} / \mathrm{mg})$ & $R_{L}$ & $R^{2}$ & $K_{F}(\mathrm{mg} / \mathrm{g})$ & $n$ & $R^{2}$ & $K_{T}(\mathrm{~J} / \mathrm{mol})$ & $f(\mathrm{~L} / \mathrm{mg})$ & $R^{2}$ \\
\hline \multirow{3}{*}{$\mathrm{MO}$} & 15 & 194.1 & 0.017 & 0.37 & 0.99 & 7.80 & 1.61 & 0.97 & 45.16 & 0.15 & 0.99 \\
\hline & 25 & 223.9 & 0.019 & 0.34 & 0.98 & 9.44 & 1.60 & 0.96 & 52.15 & 0.17 & 0.99 \\
\hline & 35 & 256.9 & 0.022 & 0.31 & 0.98 & 12.35 & 1.65 & 0.94 & 62.88 & 0.17 & 0.99 \\
\hline \multirow{3}{*}{$\mathrm{CR}$} & 15 & 314.9 & 0.038 & 0.21 & 0.99 & 24.31 & 1.81 & 0.99 & 56.77 & 0.63 & 0.97 \\
\hline & 25 & 350.2 & 0.051 & 0.16 & 0.99 & 32.03 & 1.83 & 0.97 & 70.92 & 0.63 & 0.98 \\
\hline & 35 & 389.5 & 0.062 & 0.14 & 0.99 & 40.50 & 1.84 & 0.94 & 79.13 & 0.64 & 0.94 \\
\hline
\end{tabular}

3.4. Adsorption Isotherms. The adsorption isotherms of MO and CR onto PRM were conducted using different initial dye concentrations (Figure 5). As well investigated before, the adsorption capacity of CR exceeds the adsorption capacity of MO. With the increase of initial dye concentration, the adsorption capacity of $\mathrm{CR}$ rises dramatically while the adsorption capacity of $\mathrm{MO}$ reaches plateau related to the saturation of PRM. The adsorption isotherm data fitted by Langmuir, Freundlich, and Temkin isotherm models are tabulated in Figure 6 and Table 4.

Based on the fitted $R^{2}$ value of Langmuir and Freundlich models, it is found that the Langmuir isotherm could better describe the adsorption of MO and CR onto PRM, which further proves that the adsorption of $\mathrm{MO}$ and $\mathrm{CR}$ is monolayer progress [38]. As shown in Table 4, based on the Langmuir isotherm model data, the maximum adsorption capacities are found to be $194.1,223.9$, and $256.9 \mathrm{mg} / \mathrm{g}$ for MO adsorption at 15,25 , and $35^{\circ} \mathrm{C}$ and $314.9,350.2$, and $389.5 \mathrm{mg} / \mathrm{g}$ for CR adsorption at 15,25 , and $35^{\circ} \mathrm{C}$, respectively. This suggests that the adsorption progress of both dyes is endothermic reaction, and the increase of the environment temperature accelerates the adsorption progress. The separation factor $\left(R_{L}\right)$ of the Langmuir model could reflect the adsorption progress: $R_{L}<1$ favorable, $R_{L}>1$
TABLE 5: $R_{L}$ values under different initial dye concentrations and temperatures.

\begin{tabular}{ccccccc}
\hline & \multirow{2}{*}{$T\left({ }^{\circ} \mathrm{C}\right)$} & \multicolumn{5}{c}{ Initial concentration $(\mathrm{mg} / \mathrm{L})$} \\
& & 10 & 20 & 50 & 80 & 100 \\
\hline \multirow{4}{*}{ MO } & 15 & 0.85 & 0.76 & 0.54 & 0.42 & 0.37 \\
& 25 & 0.84 & 0.72 & 0.51 & 0.40 & 0.34 \\
& 35 & 0.82 & 0.69 & 0.48 & 0.36 & 0.31 \\
& 15 & 0.72 & 0.57 & 0.34 & 0.25 & 0.21 \\
$\mathrm{CR}$ & 25 & 0.66 & 0.50 & 0.28 & 0.20 & 0.16 \\
& 35 & 0.62 & 0.45 & 0.24 & 0.17 & 0.14 \\
\hline
\end{tabular}

unfavorable, and $R_{L}=1$ linear. As shown in Table 5, the fitted $R_{L}$ values are in range of $0.31-0.85$ for $\mathrm{MO}$ adsorption and 0.14-0.72 for CR adsorption. All values are within 1, indicating the adsorption of both dyes onto PRM is favorable, effective, and reversible [39, 40]. Moreover, the fitted $R^{2}$ values of the Temkin model in MO and CR adsorption are relatively high, suggesting that there is a strong electrostatic interaction between $\mathrm{MO}, \mathrm{CR}$, and PRM which contributes to the adsorptive removal of both dyes [37, 41]. A detailed comparison table with other reported dye adsorbents is given in Table 6 and suggested the great 
TABLE 6: Detailed adsorption performance of different reported adsorbents.

\begin{tabular}{|c|c|c|c|c|}
\hline Adsorbent & Dye & $\mathrm{pH}$ & $q_{\max }(\mathrm{mg} / \mathrm{g})$ & Reference \\
\hline PRM & $\mathrm{MO}$ & 4 & 194.1 & This work \\
\hline PRM & $\mathrm{CR}$ & 4 & 314.9 & This work \\
\hline CABI nanogoethite & $\mathrm{CR}$ & 3 & 181.1 & {$[42]$} \\
\hline ZnO NRs-AC & $\mathrm{CR}$ & 7 & 142 & {$[43]$} \\
\hline$\gamma$-Fe2O3 & $\mathrm{CR}$ & 5.9 & 208.33 & {$[44]$} \\
\hline 3D hierarchical $\mathrm{PbS} / \mathrm{ZnO}$ microspheres & $\mathrm{MO}$ & 7 & 159 & {$[45]$} \\
\hline Sugar scum powder & $\mathrm{MO}$ & 7.2 & 15.24 & {$[46]$} \\
\hline
\end{tabular}

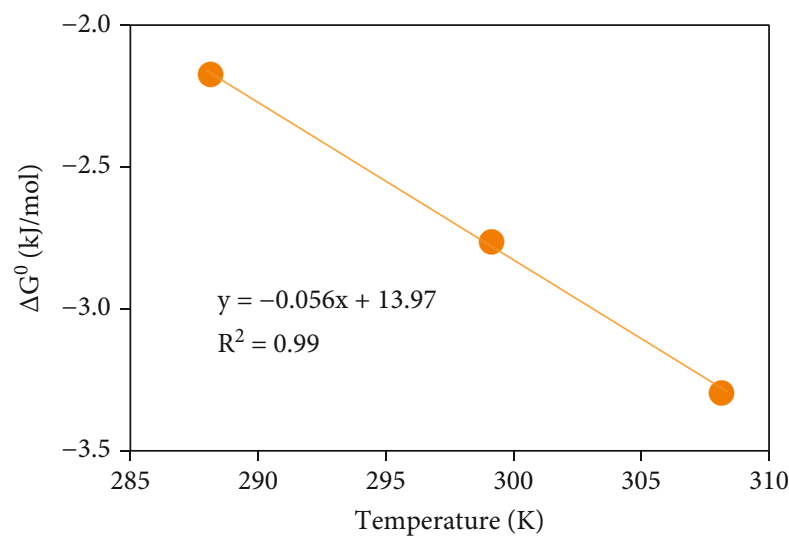

(a)

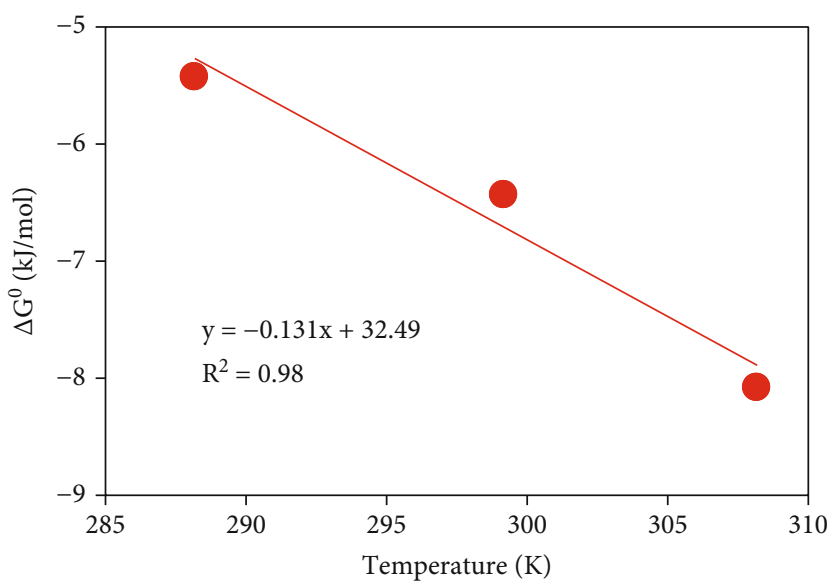

(b)

Figure 7: Thermodynamics of (a) MO and (b) CR onto PRM (experiment conditions: adsorbent dosage $=0.5 \mathrm{~g} / \mathrm{L}, \mathrm{pH}=4$ ).

TABLE 7: Fitting parameters of thermodynamic model.

\begin{tabular}{lcccc}
\hline \multirow{2}{*}{ Adsorbate } & \multirow{2}{*}{$\Delta H^{0}(\mathrm{~kJ} / \mathrm{mol})$} & $\Delta S^{0}(\mathrm{~J} /(\mathrm{mol} \mathrm{K}))$ & $288.15 \mathrm{~K}$ & \multicolumn{2}{c}{$\Delta G^{0}(\mathrm{~kJ} / \mathrm{mol})$} & $298.15 \mathrm{~K}$ & -2.76 \\
\hline MO & 13.97 & 55.98 & -2.17 & -3.30 \\
CR & 32.49 & 131.10 & -5.42 & -6.42 \\
\hline
\end{tabular}

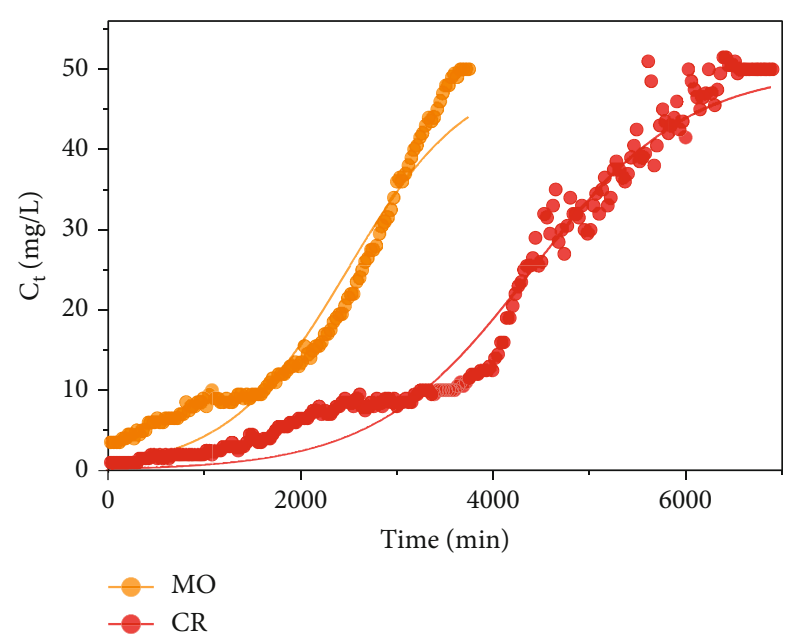

FIGURE 8: Effectivity of PRM in removing MO and CR in column study.
TABLE 8: Fitting parameters of Thomas model.

\begin{tabular}{lcccc}
\hline \multirow{2}{*}{ Adsorbate } & $q_{e}(\mathrm{mg} / \mathrm{g})$ & \multicolumn{3}{c}{ Thomas model } \\
& $k_{\mathrm{th}}(\mathrm{L} / \mathrm{mg} / \mathrm{h})$ & $q_{\mathrm{th}}(\mathrm{mg} / \mathrm{g})$ & $R^{2}$ \\
\hline MO & 28.83 & 1.48 & 31.08 & 0.94 \\
$\mathrm{CR}$ & 52.44 & 1.91 & 55.04 & 0.97 \\
\hline
\end{tabular}

performance of PRM in removing $\mathrm{MO}$ and $\mathrm{CR}$ from aqueous solutions.

3.5. Adsorption Thermodynamic. As stated in Section 3.3, the environmental temperature has a pronouncedly favored effect on the adsorption of dyes, and the adsorption progress of dyes onto PRM is accelerated by increased temperature. Thus, the detailed thermodynamic of the adsorption progress is of significance to investigating the adsorption of dyes onto PRM (Figure 7 and Table 7). In all cases, the negative values of $\Delta G^{0}$ hint that the adsorption of both dyes onto PRM is spontaneous which supports its future applications 

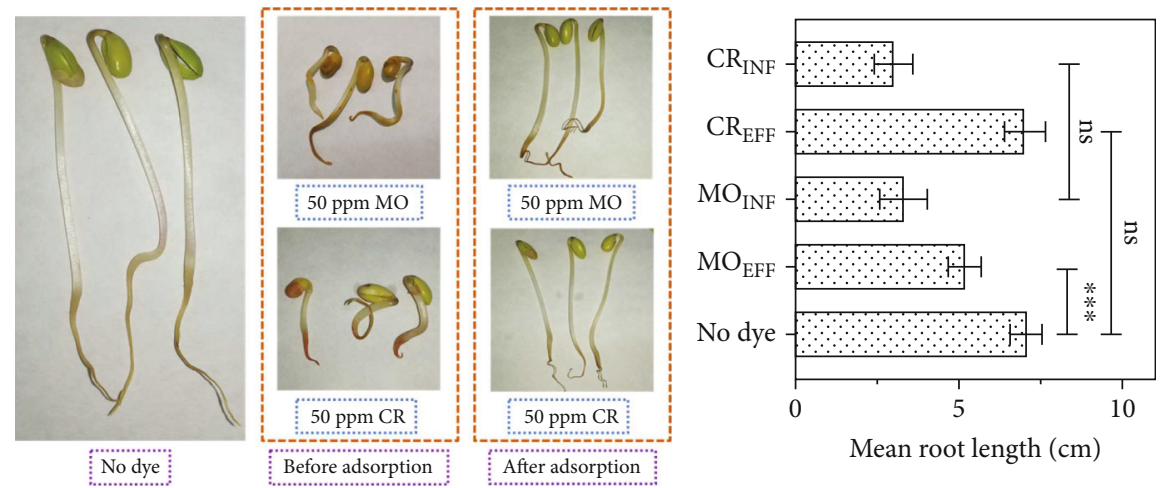

FIGURE 9: Toxicity assessment of PRM in removing MO and CR using bean sprout seeds $(t$-test, $n=10)$.

in dye adsorptive removal from aqueous solutions. The absolute value of $\Delta G^{0}$ increases with the increase of environment temperature, suggesting that the spontaneity degree increases at higher temperatures [47]. The positive values of $\Delta H^{0}$ (13.97 and $32.49 \mathrm{~kJ} / \mathrm{mol}$ for MO and CR adsorption, respectively) confirm that the adsorption progress of both dyes onto PRM is endothermic [48]. The positive values of $\Delta S^{0}$ indicate that there is an increase in randomness at the solid/liquid interface [4]. The combination of positive value for $\Delta G^{0}$ and $\Delta H^{0}$ proves that the adsorption of $\mathrm{MO}$ and $\mathrm{CR}$ onto PRM is more spontaneous and favorable at higher environment temperatures.

3.6. Column Study and Phytotoxicity Assessment. The column study is conducted in this research to further investigate the adsorption performance of both dyes in real applications. Continues treatment of $50 \mathrm{mg} / \mathrm{L}$ of $\mathrm{MO}$ and $\mathrm{CR}$ in a continuous column system is given in Figure 8. The adsorption progress of both dyes follows the same trend although the adsorption saturation time is different. For MO adsorption, the adsorbent column is exhausted at $3500 \mathrm{~min}$, while the adsorption saturation time for CR is more than $6000 \mathrm{~min}$. Specifically, the concentrations of MO effluents increase slowly in the first $2000 \mathrm{~min}$ ( $\sim 180$ bed volumes) while a more rapid increase is observed afterwards. In contrast, no evident increase is observed before $4000 \mathrm{~min}$ for CR adsorption column ( $\sim 360$ bed volumes), indicating that the CR removal in column study is also better than MO removal which shares the same result from batch studies.

In order to have quantitative evaluations and thus have solid predictions on the adsorption performance in column studies and future applications, the Thomas model is used and its detailed parameters are summarized [28]. As shown in Table 8, the adsorption rate of the CR is higher than MO in column study which is in accordance with the fitted kinetic parameters in batch studies. In addition, the maximum adsorption capacity for MO and CR is 31.08 and $55.04 \mathrm{mg} / \mathrm{g}$, respectively, and it is not surprising that the adsorption capacity in column studies is considerably lower than in batch studies ( $20 \%$ of batch studies) [49]. Moreover, the calculated experimental adsorption capacity $q_{e}$ is close to the theoretical adsorption capacity $q_{\mathrm{th}}$, suggesting the Thomas model can describe the column adsorption performance appropriately.
The effluents from the column study are used for further toxicity assessment (collected around $2000 \mathrm{~min}$ ). The germination of bean sprouts is used as the indicator of PRM effectivity for eliminating anionic dyes in terms of aqueous toxicity. In this research, the deionized water is used as control group (no dye) and the influent (50 ppm for MO and $\mathrm{CR}$ ) and effluent from the column study are used. After germinating the bean sprouts for 3 days under no light condition, the length of the roots is measured and summarized in Figure 9. As shown in Figure 9(a), the mean root length of the control group is $7.06 \mathrm{~cm}$ and the length is reduced to 3.30 and $3.01 \mathrm{~cm}$, for $\mathrm{MO}$ influents $\left(\mathrm{MO}_{\mathrm{INF}}\right)$ and $\mathrm{CR}$ influents $\left(\mathrm{CR}_{\mathrm{INF}}\right)$, respectively. For the bean sprouts treated with $\mathrm{MO}$ effluents $\left(\mathrm{MO}_{\mathrm{EFF}}\right)$ and $\mathrm{CR}$ effluents $\left(\mathrm{CR}_{\mathrm{EFF}}\right)$, the mean root length is improved to 5.18 and $7.00 \mathrm{~cm}$, respectively. This confirms the effectivity of PRM in reducing the toxicity of treated solutions. Moreover, the $t$-test suggests that the length difference between control and $\mathrm{CR}_{\mathrm{EFF}}$ is not significant but the difference between the control group and $\mathrm{MO}_{\mathrm{EFF}}$ is significant. Conclusively, it can be reported that the PRM can treat the CR dyes into nontoxic solutions like deionized water (in terms of phytotoxicity) and $\mathrm{MO}$ dye into relatively toxic solutions, under the experimental conditions as conducted in this research.

\section{Conclusion}

In this study, the adsorption performance of two anionic dyes by a red mud-based adsorbent was investigated. The removal of dyes (CR and $\mathrm{MO}$ ) from aqueous solution by the red mud-based adsorbent was investigated by batch and column studies. The successful loading of the polypyrrole onto the surface of red mud helps to improve the adsorption capacity of the adsorbent: $194.1 \mathrm{mg} / \mathrm{g}$ for MO adsorption and $314.9 \mathrm{mg} / \mathrm{g}$ for $\mathrm{CR}$ adsorption at $15^{\circ} \mathrm{C}$, respectively. The highest adsorption capacity was obtained at $\mathrm{pH} 4$ and decreased with the increase of $\mathrm{pH}$. Thermodynamic results suggested that the adsorption progress of MO and CR onto PRM was endothermic and spontaneous. Phytotoxicity assessment of the column study effluents confirmed the effectivity of PRM in eliminating the dye toxicity in terms of germination of bean sprouts. Therefore, the PRM adsorbent could be applied as a promising adsorbent for decolorization in aqueous solutions. 


\section{Data Availability}

The data that support the findings of this study are available on request from the corresponding author, Changqing Liu.

\section{Conflicts of Interest}

The authors declare that there is no conflict of interest regarding the publication of this paper.

\section{Authors' Contributions}

Conceptualization was done by Ya-nan Luan and Changqing Liu. Data curation was contributed by Feng Zhang, Yue Yin, and Chunlei Qiao. Funding acquisition was contributed by Changqing Liu. Investigation was conducted by Feng Zhang, Yue Yin, Ya-nan Luan, Mengyan Guo, and Yihua Xiao. Methodology was done by Yue Yin. Project administration was done by Changqing Liu. Software was contributed by Chunlei Qiao and Mengyan Guo. Writing_-original draft was contributed by Feng Zhang and Yue Yin. Writing-review and editing was contributed by Yihua Xiao and Changqing Liu. Feng Zhang and Yue Yin contributed equally to this work.

\section{Acknowledgments}

This study was funded by the Major Science and Technology Innovation Project of Shandong Province (Grant No. 2018YFJH0902) and the Taishan Scholar Foundation of Shandong Province (Grant No. tsqn201909126).

\section{Supplementary Materials}

Fig. S1: laboratory column study schematic flow chart. Fig. S2: surface morphology of raw red mud (a) and PRM (b). Fig. S3: FT-IR spectrum of raw red mud and PRM. Fig. S4: surface morphology and EDS of PRM after adsorption of MO (a, b) and CR (c, d). Fig. S5: detailed surface morphology of PRM after adsorption of MO (a-d) and CR (e-h) at different magnifications. (Supplementary Materials)

\section{References}

[1] I. Ali, O. M. L. Alharbi, Z. A. Alothman, and A. Alwarthan, "Facile and eco-friendly synthesis of functionalized iron nanoparticles for cyanazine removal in water," Colloids and Surfaces. B, Biointerfaces, vol. 171, pp. 606-613, 2018.

[2] I. Ali, O. M. L. Alharbi, Z. A. Alothman, and A. Y. Badjah, "Kinetics, thermodynamics, and modeling of amido black dye photodegradation in water using $\mathrm{co} / \mathrm{TiO}_{2}$ nanoparticles," Photochemistry and Photobiology, vol. 94, pp. 935-941, 2018.

[3] P. Kumar, R. Agnihotri, K. L. Wasewar, H. Uslu, and C. Yoo, "Status of adsorptive removal of dye from textile industry effluent," Desalination and Water Treatment, vol. 50, pp. 226-244, 2012.

[4] T. Kekes and C. Tzia, "Adsorption of indigo carmine on functional chitosan and $\beta$-cyclodextrin/chitosan beads: equilibrium, kinetics and mechanism studies," Journal of Environmental Management, vol. 262, p. 110372, 2020.

[5] A. Kausar, R. Shahzad, J. Iqbal, N. Muhammad, S. M. Ibrahim, and M. Iqbal, "Development of new organic-inorganic, hybrid bionanocomposite from cellulose and clay for enhanced removal of Drimarine Yellow HF-3GL dye," International Journal of Biological Macromolecules, vol. 149, pp. 1059$1071,2020$.

[6] S. Liu, Y. Ding, P. Li et al., "Adsorption of the anionic dye Congo red from aqueous solution onto natural zeolites modified with N, N-dimethyl dehydroabietylamine oxide," Chemical Engineering Journal, vol. 248, pp. 135-144, 2014.

[7] M. Abbas, M. Adil, S. Ehtisham-ul-Haque et al., "Vibrio fischeri bioluminescence inhibition assay for ecotoxicity assessment: a review," Sci. Total Environ., vol. 626, pp. 12951309, 2018.

[8] H. Mahmoodian, O. Moradi, B. Shariatzadeha et al., "Enhanced removal of methyl orange from aqueous solutions by poly HEMA-chitosan-MWCNT nano-composite," Journal of Molecular Liquids, vol. 202, pp. 189-198, 2015.

[9] R. Li, B. Gao, K. Guo, Q. Yue, H. Zheng, and Y. Wang, "Effects of papermaking sludge-based polymer on coagulation behavior in the disperse and reactive dyes wastewater treatment," Bioresource Technology, vol. 240, pp. 59-67, 2017.

[10] O. Türgay, G. Ersöz, S. Atalay, J. Forss, and U. Welander, "The treatment of azo dyes found in textile industry wastewater by anaerobic biological method and chemical oxidation," Separation and Purification Technology, vol. 79, pp. 26-33, 2011.

[11] C. H. Nguyen, M. L. Tran, T. T. Van Tran, and R.-S. S. Juang, "Enhanced removal of various dyes from aqueous solutions by $\mathrm{UV}$ and simulated solar photocatalysis over $\mathrm{TiO} 2 / \mathrm{ZnO} / \mathrm{rGO}$ composites," Separation and Purification Technology, vol. 232, p. 115962, 2020.

[12] J. Stejskal, "Interaction of conducting polymers, polyaniline and polypyrrole, with organic dyes: polymer morphology control, dye adsorption and photocatalytic decomposition," Chemical Papers, vol. 74, no. 1, pp. 1-54, 2020.

[13] M. A. Khan, A. A. Alqadami, S. M. Wabaidur et al., "Oil industry waste based non-magnetic and magnetic hydrochar to sequester potentially toxic post-transition metal ions from water," Journal of Hazardous Materials, vol. 400, p. 123247, 2020.

[14] E. R. Kenawy, A. A. Ghfar, S. M. Wabaidur et al., "Cetyltrimethylammonium bromide intercalated and branched polyhydroxystyrene functionalized montmorillonite clay to sequester cationic dyes," Journal of Environmental Management, vol. 219, pp. 285-293, 2018.

[15] R. Zhang, M. Ma, Q. Zhang, F. Dong, and Y. Zhou, "Multifunctional g-C3N4/graphene oxide wrapped sponge monoliths as highly efficient adsorbent and photocatalyst," Applied Catalysis B: Environmental, vol. 235, pp. 17-25, 2018.

[16] C. Wu, L. Huang, S. G. Xue et al., "Arsenic sorption by red mud-modified biochar produced from rice straw," Environmental Science and Pollution Research, vol. 24, no. 22, pp. 18168-18178, 2017.

[17] N. B. A, K. M. Krishna, K. Kalpana, and K. Ravindhranath, "Removal of fluoride from water using $\mathrm{H}_{2} \mathrm{O}_{2}$-treated fine red mud doped in Zn-alginate beads as adsorbent," Journal of Environmental Chemical Engineering, vol. 6, no. 1, pp. 906916, 2018.

[18] I. Akin, G. Arslan, A. Tor, M. Ersoz, and Y. Cengeloglu, "Arsenic $(V)$ removal from underground water by magnetic nanoparticles synthesized from waste red mud," Journal of Hazardous Materials, vol. 235-236, pp. 62-68, 2012. 
[19] Y. Wang, S. Gong, Y. Li, Z. Li, and J. Fu, “Adsorptive removal of tetracycline by sustainable ceramsite substrate from bentonite/red mud/pine sawdust," Scientific Reports, vol. 10, pp. 118,2020 .

[20] Y. Wang, Y. Yu, H. Li, and C. Shen, "Comparison study of phosphorus adsorption on different waste solids: Fly ash, red mud and ferric-alum water treatment residues," Journal of Environmental Sciences (China), vol. 50, pp. 79-86, 2016.

[21] J. Ye, X. Cong, P. Zhang et al., "Phosphate adsorption onto granular-acid-activated-neutralized red mud: parameter optimization, kinetics, isotherms, and mechanism analysis," Water, Air, and Soil Pollution, vol. 226, no. 9, 2015.

[22] J. Li, L. Xu, P. Sun et al., "Novel application of red mud: facile hydrothermal-thermal conversion synthesis of hierarchical porous $\mathrm{AlOOH}$ and $\mathrm{Al} 2 \mathrm{O} 3$ microspheres as adsorbents for dye removal," Chemical Engineering Journal, vol. 321, pp. 622-634, 2017.

[23] X. Li, M. Ji, L. D. Nghiem et al., "A novel red mud adsorbent for phosphorus and diclofenac removal from wastewater," Journal of Molecular Liquids, vol. 303, p. 112286, 2020.

[24] C. Li, N. Chen, Y. Zhao, R. Li, and C. Feng, "Polypyrrolegrafted peanut shell biological carbon as a potential sorbent for fluoride removal: sorption capability and mechanism," Chemosphere, vol. 163, pp. 81-89, 2016.

[25] C. Patra, R. Gupta, D. Bedadeep, and S. Narayanasamy, "Surface treated acid-activated carbon for adsorption of anionic azo dyes from single and binary adsorptive systems: a detail insight," Environmental Pollution, vol. 266, p. 115102, 2020.

[26] A. Naga Babu, T. Raja Sree, D. Srinivasa Reddy, G. Suresh Kumar, and G. V. Krishna Mohan, "Experimental and statistical analysis of As (III) adsorption from contaminated water using activated red mud doped calcium-alginate beads," Environ. Technol. (United Kingdom), vol. 42, pp. 1-34, 2021.

[27] J. Jang and D. S. Lee, "Effective phosphorus removal using chitosan/Ca-organically modified montmorillonite beads in batch and fixed-bed column studies," Journal of Hazardous Materials, vol. 375, pp. 9-18, 2019.

[28] A. F. Santos, A. L. Arim, D. V. Lopes, L. M. Gando-Ferreira, and M. J. Quina, "Recovery of phosphate from aqueous solutions using calcined eggshell as an eco-friendly adsorbent," Journal of Environmental Management, vol. 238, pp. 451459, 2019.

[29] S. Hong, F. S. Cannon, P. Hou, T. Byrne, and C. Nieto-Delgado, "Adsorptive removal of sulfate from acid mine drainage by polypyrrole modified activated carbons: effects of polypyrrole deposition protocols and activated carbon source," Chemosphere, vol. 184, pp. 429-437, 2017.

[30] X. Yang, Y. Li, H. Gao, C. Wang, X. Zhang, and H. Zhou, "One-step fabrication of chitosan- $\mathrm{Fe}(\mathrm{OH}) 3$ beads for efficient adsorption of anionic dyes," International Journal of Biological Macromolecules, vol. 117, pp. 30-41, 2018.

[31] M. Naushad, G. Sharma, and Z. A. Alothman, "Photodegradation of toxic dye using Gum Arabic-crosslinked-poly(acrylamide)/Ni(OH)2/FeOOH nanocomposites hydrogel," Journal of Cleaner Production, vol. 241, p. 118263, 2019.

[32] W. A. Khanday, M. J. Ahmed, P. U. Okoye, E. H. Hummadi, and B. H. Hameed, "Single-step pyrolysis of phosphoric acidactivated chitin for efficient adsorption of cephalexin antibiotic," Bioresource Technology, vol. 280, pp. 255-259, 2019.

[33] W. Qi, Y. Zhao, X. Zheng, M. Ji, and Z. Zhang, "Adsorption behavior and mechanism of $\mathrm{Cr}$ (VI) using Sakura waste from aqueous solution," Applied Surface Science, vol. 360, pp. 470476, 2016.

[34] R. Liu, L. Chi, X. Wang et al., "Effective and selective adsorption of phosphate from aqueous solution via trivalentmetals-based amino-MIL-101 MOFs," Chemical Engineering Journal, vol. 357, pp. 159-168, 2019.

[35] G. Fu, Y. Zhao, S. Zhou, C. Chen, Y. Zhong, and Y. Xu, "Efficient removal of nitrogen and phosphorus in aqueous solutions using modified water treatment residuals-sodium alginate beads," Environmental Science and Pollution Research, 2021.

[36] W. Ding, X. Wan, H. Zheng, Y. Wu, and S. Muhammad, "Sulfite-assisted oxidation/adsorption coupled with a $\mathrm{TiO} 2$ supported $\mathrm{CuO}$ composite for rapid arsenic removal: performance and mechanistic studies," Journal of Hazardous Materials, vol. 413, p. 125449, 2021.

[37] I. Khatri, J. Amar, and J. Amar, "Prediction and optimization of adsorption properties for Cs + on [email protected] LDHs hollow spheres from aqueous solution: Kinetics, isotherms, and BBD model," Journal of Hazardous Materials, vol. 401, article 123374, 2021.

[38] Y. X. Zhang and Y. Jia, "Fluoride adsorption on manganese carbonate: ion-exchange based on the surface carbonate-like groups and hydroxyl groups," Journal of Colloid and Interface Science, vol. 510, pp. 407-417, 2018.

[39] J. Lin, Y. Wang, Y. Zhan, and Z. Zhang, "Magnetite-modified activated carbon based capping and mixing technology for sedimentary phosphorus release control," Journal of Environmental Management, vol. 248, p. 109287, 2019.

[40] V. M. Tangde, S. S. Prajapati, B. B. Mandal, and N. P. Kulkarni, "Study of kinetics and thermodynamics of removal of phosphate from aqueous solution using activated red mud," Int. J. Environ. Res., vol. 11, no. 1, pp. 39-47, 2017.

[41] A. O. Babatunde and Y. Q. Zhao, "Equilibrium and kinetic analysis of phosphorus adsorption from aqueous solution using waste alum sludge," Journal of Hazardous Materials, vol. 184, no. 1-3, pp. 746-752, 2010.

[42] V. S. Munagapati and D.-S. Kim, "Equilibrium isotherms, kinetics, and thermodynamics studies for Congo red adsorption using calcium alginate beads impregnated with nano-goethite," Ecotoxicology and Environmental Safety, vol. 141, pp. 226-234, 2017.

[43] M. Ghaedi, M. N. Biyareh, S. N. Kokhdan et al., "Comparison of the efficiency of palladium and silver nanoparticles loaded on activated carbon and zinc oxide nanorods loaded on activated carbon as new adsorbents for removal of Congo red from aqueous solution: kinetic and isotherm study," Materials Science and Engineering: C, vol. 32, no. 4, pp. 725-734, 2012.

[44] A. Afkhami and R. Moosavi, "Adsorptive removal of Congo red, a carcinogenic textile dye, from aqueous solutions by maghemite nanoparticles," Journal of Hazardous Materials, vol. 174, no. 1-3, pp. 398-403, 2010.

[45] S. Liu, W. Wang, Y. Cheng et al., "Methyl orange adsorption from aqueous solutions on $3 \mathrm{D}$ hierarchical $\mathrm{PbS} / \mathrm{ZnO}$ microspheres," Journal of Colloid and Interface Science, vol. 574, pp. 410-420, 2020.

[46] N. Elhadiri, M. Benchanaa, and R. Chikri, "Adsorption thermodynamic and kinetic studies of methyl orange onto sugar scum powder as a low-cost inorganic adsorbent," Journal of Chemistry, vol. 2020, 10 pages, 2020. 
[47] Y. Y. Hu, C. Pan, X. Zheng et al., "Prediction and optimization of adsorption properties for Cs + on [email protected] LDHs hollow spheres from aqueous solution: Kinetics, isotherms, and BBD model," Journal of Hazardous Materials, vol. 401, article 123374, 2021.

[48] C. Li, Q. Yang, S. Lu, and Y. Liu, “Adsorption and mechanism study for phosphonate antiscalant HEDP removal from reverse osmosis concentrates by magnetic $\mathrm{La} / \mathrm{Zn} / \mathrm{Fe}_{3} \mathrm{O}_{4} @ \mathrm{PAC}$ composite," Colloids and Surfaces A: Physicochemical and Engineering Aspects, vol. 613, p. 126056, 2021.

[49] O. Callery, M. G. G. Healy, F. Rognard, L. Barthelemy, and R. B. B. Brennan, "Evaluating the long-term performance of low-cost adsorbents using small-scale adsorption column experiments," Water Research, vol. 101, pp. 429-440, 2016. 